\title{
Efficacy and safety of methotrexate in alopecia areata*
}

\author{
Mariana Hammerschmidt ${ }^{1}$
}

Fabiane Mulinari Brenner ${ }^{1}$

DOI: http://dx.doi.org/10.1590/abd1806-4841.20142869

\begin{abstract}
BACKGROUND: Alopecia areata is a chronic disorder of the hair follicles and nails, of unknown etiology, with clear autoimmune components and genetic factors. Several therapeutic options have been suggested; however, no treatment is able to modify the disease course. Methotrexate is an immunosuppressant used in various dermatoses and recently introduced as a therapeutic option for alopecia areata.

OBJECTIVES: To evaluate the efficacy and safety of methotrexate in alopecia areata.

METHODS: In a retrospective, non-controlled study, we evaluated 31 patients with alopecia areata in current or prior treatment with methotrexate to assess the therapeutic response according to sex, age, pattern of alopecia areata, disease duration, cumulative dose of methotrexate, use of systemic corticosteroids or other treatments, and drug safety.

RESULTS: Regrowth greater than $50 \%$ was observed in $67.7 \%$ of patients, with the best responses observed in those with $<5$ years of disease progression (79\%), age over 40 years (73.3\%), male patients $(72.8 \%)$, cumulative dose of methotrexate $1000-1500 \mathrm{mg}$, and multifocal alopecia areata $(93 \%)$. Among patients receiving systemic corticosteroids in combination with methotrexate, $77.3 \%$ had greater than 50\% regrowth, compared with $44.4 \%$ in those who used methotrexate alone. The therapeutic dose ranged from $10-25 \mathrm{mg} /$ week. No patient had serious adverse effects. Relapse was observed in $33.3 \%$ of patients with more than $50 \%$ regrowth.

CONCLUSION: Methotrexate appears to be a promising and safe medication for the treatment of severe alopecia areata when used alone or in combination with corticosteroids.
\end{abstract}

Keywords: Alopecia Areata; Efficacy; Methotrexate

\section{INTRODUCTION}

Alopecia areata (AA) is a chronic, multifactorial condition of the hair follicles and nails, of unknown etiology, with clear genetic and autoimmune components. ${ }^{1,2}$ It is a common complaint at the dermatologist's office, accounting for 0.7 to $3.8 \%$ of visits. ${ }^{2,3}$ Depending on the number and distribution of lesions and the extent of involvement, it is classified clinically into the following patterns: unifocal, multifocal, ophiasis, totalis, universalis, sisaipho (or ophiasis inversus), reticular, and diffuse. ${ }^{1}$

Regarding the natural history of the disease, hair regrowth occurs in $34 \%$ to $50 \%$ of patients within 1 year, whereas $15 \%$ to $25 \%$ will progress to AA totalis (loss of all scalp hair). There is a direct association between the severity of AA and the long-term prognosis. Available treatments may induce regrowth, but do not modify the disease course. ${ }^{4}$

Potential autoimmune mechanisms involved in the pathogenesis of AA include sensitization of T lymphocytes, particularly CD8+ T cells, to follicular antigens. Activation of the lymphocytes that compose the perifollicular infiltrate characteristic of $\mathrm{AA}$ induces release of several Th1 cytokines - interleukin (IL)-1 alpha, IL-1 beta, and tumor necrosis factor (TNF) alpha - capable of inhibiting hair follicle growth and arresting hair synthesis, with early termination of anagen. ${ }^{1,25,6}$

Several treatment options have been suggested for AA, but there is a paucity of randomized, doubleblind, placebo-controlled trials, and, as noted above, no therapy is able to modify the course of the disease. ${ }^{7}$

Methotrexate (MTX) is an immunosuppressant agent of the folic acid antagonist class that is used in the treatment of several dermatoses. Most dermatologists are used to its prescription and monitoring, particularly in the treatment of psoriasis. MTX was recently introduced as a therapeutic option for AA..$^{8,9,10,11}$

\section{Objectives}

To assess the efficacy and safety of MTX in AA, whether as monotherapy or in combination with other treatment modalities, such as systemic or intralesional corticosteroids; and to assess therapeutic response according to sex, age, pattern of AA, disease duration, cumulative MTX dose, and duration of therapy.

\footnotetext{
Received on 15.06.13

Approved by the Advisory Board and accepted for publication on 09.09.2013.

* Work performed at Hospital de Clínicas - Universidade Federal do Paraná (UFPR) - Curitiba (PR), Brazil.

Financial support: None.

Conflict of interests: None.

Universidade Federal do Paraná (UFPR) - Curitiba (PR), Brazil.

(C)2014 by Anais Brasileiros de Dermatologia
} 


\section{METHODS}

This retrospective study evaluated 31 patients with AA seen at the outpatient hair disorders clinic of Hospital de Clínicas de Curitiba (state of Paraná, Brazil) and at private dermatology practices in Curitiba who were on current or prior MTX therapy. The sample comprised patients with extensive forms of AA (multifocal, universalis, totalis, and diffuse), refractory to previous treatment attempts, who were over 15 years of age.

The following characteristics were considered as criteria for MTX prescription: absence of hepatic impairment (confirmed by laboratory testing), absence of active tuberculosis infection (confirmed by clinical examination or PPD and chest X-ray), absence of pregnancy, and COCP (combined oral contraceptive) use. Furthermore, patients were informed of possible side effects and MTX was only prescribed after patient consent had been obtained.

We evaluated the following parameters: disease duration, concomitant therapies (including systemic corticosteroid therapy), pattern of alopecia, weekly MTX dose, cumulative dose of MTX in mg (stratified into predetermined ranges: <500 mg; 501-1000 mg; 1001-1500 mg; 1501-2000 mg; 2001-2500 mg; and
$>2500 \mathrm{mg}$ ), hematologic and/or hepatic adverse events, treatment duration, and therapeutic response. Regrowth was stratified into five categories: $0-25 \%$; $26-50 \%$; $51-75 \%$; 76-99\%; and 100\%. All patients underwent a comprehensive outpatient workup, which included a complete blood count and measurement of transaminase, creatinine, bilirubin, and gamma-glutamyl transpeptidase levels, at baseline, 1 month, and every 3 months thereafter during the follow-up period. In some patients, a chest $\mathrm{X}$-ray, PPD skin testing, and a hepatitis serology panel were also performed before treatment. Patients who received a total cumulative dose of MTX $>2 \mathrm{~g}$ underwent abdominal ultrasound and liver biopsy.

\section{RESULTS}

The median patient age was 40 years (range, 1572 years), and the median disease duration was 4 years (range, 0.17-32 years). Of the patients assessed, $66.6 \%$ were female and $33.3 \%$ were male (Table 1 ). The most common pattern of AA was multifocal (48.39\%), followed by universalis $(35.48 \%)$, diffuse $(9.67 \%)$, and totalis $(6.45 \%)$.

TABLE 1: Key clinical and treatment-related characteristics of the sample

\begin{tabular}{|c|c|c|c|c|c|}
\hline Case & Sex & AA type & Systemic cortico-steroid therapy & Total CD & $\%$ improvement \\
\hline 1 & Female & Multifocal & No & $1-499$ & $26-50 \%$ \\
\hline 2 & Male & Universalis & Yes & $500-999$ & $51-75 \%$ \\
\hline 3 & Female & Universalis & No & $3000-3499$ & $26-50 \%$ \\
\hline 4 & Female & Multifocal & No & $1000-1499$ & $100 \%$ \\
\hline 5 & Female & Universalis & Yes & $2500-2999$ & $0 \%$ \\
\hline 6 & Male & Multifocal & No & $1000-1499$ & $76-99 \%$ \\
\hline 7 & Female & Multifocal & Yes & $2000-2499$ & $100 \%$ \\
\hline 8 & Male & Multifocal & Yes & $1000-1499$ & $100 \%$ \\
\hline 9 & Male & Universalis & Yes & 1000-1499 & $0 \%$ \\
\hline 10 & Female & Multifocal & No & 1500-1999 & $76-99 \%$ \\
\hline 11 & Female & Multifocal & Yes & $1500-1999$ & $100 \%$ \\
\hline 12 & Female & Universalis & Yes & $2000-2499$ & $76-99 \%$ \\
\hline 13 & Male & Multifocal & Yes & $500-999$ & $100 \%$ \\
\hline 14 & Male & Universalis & Yes & $1500-1999$ & $0 \%$ \\
\hline 15 & Male & Multifocal & Yes & $500-999$ & $76-99 \%$ \\
\hline 16 & Female & Totalis & Yes & $1000-1499$ & $51-75 \%$ \\
\hline 17 & Female & Multifocal & No & $500-999$ & $76-99 \%$ \\
\hline 18 & Male & Multifocal & Yes & 500-999 & $51-75 \%$ \\
\hline 19 & Female & Universalis & No & $500-999$ & $26-50 \%$ \\
\hline 20 & Female & Diffuse & No & $1-499$ & $0 \%$ \\
\hline 21 & Male & Universalis & Yes & $1-499$ & $51-75 \%$ \\
\hline 22 & Female & Universalis & Yes & $1-499$ & $76-99 \%$ \\
\hline 23 & Female & Diffuse & Yes & $500-999$ & $26-50 \%$ \\
\hline 24 & Female & Multifocal & Yes & $1-499$ & $51-75 \%$ \\
\hline 25 & Female & Multifocal & Yes & $1-499$ & $100 \%$ \\
\hline 26 & Female & Totalis & No & $1-499$ & $26-50 \%$ \\
\hline 27 & Female & Diffuse & Yes & $1500-1999$ & $76-99 \%$ \\
\hline 28 & Male & Multifocal & Yes & 1000-1499 & $76-99 \%$ \\
\hline 29 & Female & Multifocal & Yes & 500-999 & $76-99 \%$ \\
\hline 30 & Female & Universalis & Yes & $1-499$ & $51-75 \%$ \\
\hline 31 & Male & Universalis & Yes & $1-499$ & $26-50 \%$ \\
\hline
\end{tabular}


Most patients had received previous trials of therapy, such as topical sensitizers (58\%) and systemic corticosteroids (51.6\%), either unsuccessfully or with disease recurrence after withdrawal of treatment.

The starting dose of MTX ranged from 10 to 25 $\mathrm{mg}( \pm 15 \mathrm{mg})$, as did the median therapeutic dose $( \pm 20$ $\mathrm{mg})$. The cumulative dose to onset of response ranged from 30 to $630 \mathrm{mg}( \pm 180 \mathrm{mg})$. The distribution of cumulative doses in the sample was as follows: $<500$ $\mathrm{mg}$, 25.8\%; 501-1000 mg, 29\%; 1001-1500 mg, 19.3\%; $1501-2000 \mathrm{mg}, 12.9 \%$; and $>2000 \mathrm{mg}, 12.9 \%$.

A therapeutic response with regrowth over $>50 \%$ of the scalp (Figures 1, 2, and 3), considered cosmetically acceptable, was observed in $67.7 \%(n=21)$ of all patients, with $29 \%(\mathrm{n}=9)$ achieving $76-99 \%$ regrowth and $19.3 \%(n=6)$ achieving $100 \%$ regrowth. The frequency of regrowth was significantly greater among men $(72.8 \%, \mathrm{p}>0.05)$, patients aged 40 years or older $(73.3 \%, \mathrm{p}>0.05)$, and those taking a cumulative MTX dose of 1001-1500 mg (83.3\%, p>0.05) (Table 2).

Furthermore, superior responses were observed in patients with a disease duration $<5$ years (79\% regrowth), with the overall regrowth rate dropping to $50 \%$ in patients with disease duration $>5$ years. There was a significant inverse association between disease duration and percent improvement $(p=0.02)$; the shorter the disease duration, the greater the improvement. Regarding AA patterns, $>50 \%$ regrowth was observed in $93.3 \%(n=14)$ with multifocal, $45.4 \%(n=5)$ with universalis, $50 \%(n=1)$ with totalis, and $33.3 \%(n=1)$ with diffuse AA. The difference between the two most prevalent forms, universalis and multifocal, was significant $(\mathrm{p}=0.018)$ (Table 3$)$.
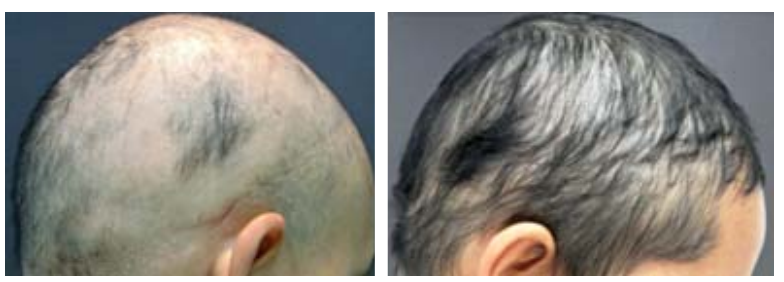

FiguRE 1: Multifocal AA. Left, before treatment; right, after a cumulative dose of $180 \mathrm{mg}$ methotrexate in combination with corticosteroids ( $80 \%$ regrowth)
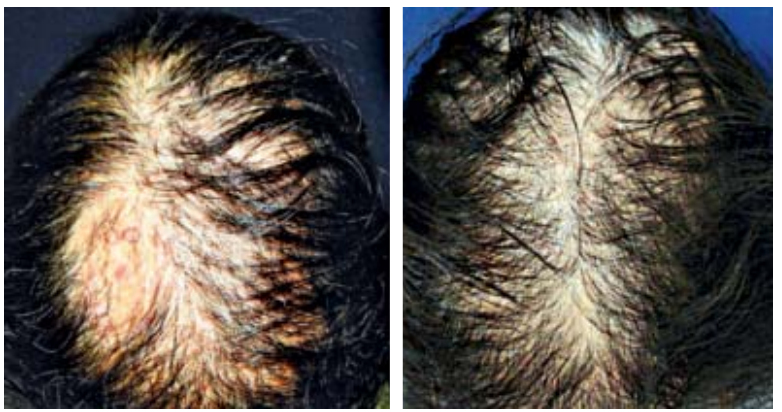

FiguRE 2: AA totalis. Left, before; right, after a cumulative dose of $320 \mathrm{mg}$ methotrexate in combination with corticosteroids $(90 \%$ regrowth).
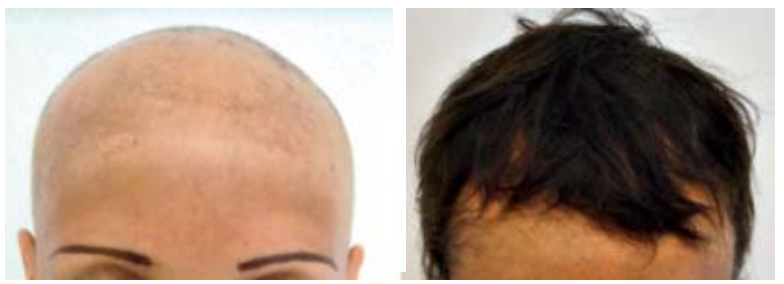

Figure 3: Diffuse AA, top view. Left, before; right, after a cumulative dose of $930 \mathrm{mg}$ methotrexate in combination with corticosteroid during the first 4 months of therapy (60\% regrowth).

TABLE 2: Percent regrowth achieved by cumulative methotrexate dose

\begin{tabular}{|c|c|c|c|c|c|c|}
\hline \multicolumn{7}{|c|}{ CUMULATIVE METHOTREXATE DOSE } \\
\hline \% REGROWTH & $<500$ & $501-1000$ & $1001-1500$ & $1501-2000$ & $>2000$ & TOTAL \\
\hline $0 \%$ & 1 & 0 & 1 & 1 & 1 & 4 \\
\hline $0-25 \%$ & 0 & 0 & 0 & 0 & 0 & 0 \\
\hline $25-50 \%$ & 2 & 3 & 0 & 0 & 1 & 6 \\
\hline $50-75 \%$ & 3 & 2 & 1 & 0 & 0 & 6 \\
\hline $75-100 \%$ & 1 & 3 & 2 & 2 & 1 & 9 \\
\hline $100 \%$ & 1 & 1 & 2 & 1 & 1 & 6 \\
\hline Total & 8 & 9 & 6 & 4 & 4 & 31 \\
\hline
\end{tabular}

TABLE 3: Distribution of regrowth in the different types of alopecia areata represented in the sample, stratified by prevalence

\begin{tabular}{|c|c|c|c|c|}
\hline \multirow[t]{2}{*}{ AA type } & \multicolumn{2}{|c|}{$\begin{array}{l}\text { Sample-wide } \\
\text { prevalence }(\%)\end{array}$} & \multicolumn{2}{|c|}{$>50 \%$ regrowth } \\
\hline & $\%$ & $\mathbf{N}$ & $\%$ & $\mathbf{N}$ \\
\hline Multifocal & 48.3 & 15 & 93 & 14 \\
\hline Universalis & 35.4 & 11 & 45 & 5 \\
\hline Diffuse & 9.6 & 3 & 33 & 1 \\
\hline Totalis & 6 & 2 & 50 & 1 \\
\hline
\end{tabular}

The treatments combined with MTX included topical minoxidil, intralesional corticosteroids, and systemic corticosteroids (prednisone). Only one patient did not use any combination therapy. The most common combination therapy added to MTX was topical minoxidil + systemic corticosteroid $(29 \%)$.

Among the patients who used systemic corticosteroids in combination with MTX (70\%), 77.3\% experienced $>50 \%$ regrowth. Most used steroids only 
during the first months of treatment. Among those who did not use systemic corticosteroids in combination with MTX (30\%), only $44.4 \%$ experienced $>50 \%$ regrowth. There was no significant association between corticosteroid therapy and treatment response. The duration of combination corticosteroid therapy ranged from 1 to 12 months ( \pm 4 months), and the dose, from 20 to $30 \mathrm{mg} /$ day $( \pm 30 \mathrm{mg})$.

All patients underwent complete blood count and liver and kidney function tests at baseline. Nine also underwent hepatitis serologies (all non-reagent) and nine underwent PPD testing, of whom three were strongly reactive, despite normal chest $\mathrm{X}$-ray.

All patients received folic acid supplementation ( $5 \mathrm{mg}$ ) at least one weekly, on the day after MTX. Folic acid administration was increased to three weekly doses in patients with MTX intolerance or gastric or hematologic adverse effects.

Regarding treatment tolerance, only three patients $(9.3 \%)$ reported gastrointestinal side effects (nausea, epigastric pain, and diarrhea), which were managed by scaling up folic acid supplementation and dividing the MTX dose, with improvement of symptoms in two patients; only one required treatment discontinuation.

Hematologic adverse effects (mild to moderate leukopenia, without clinical significance) were observed in $9.7 \%(n=3)$ of patients, and improved after folic acid supplementation was increased.

Hepatic adverse effects (mild, transient increase in transaminases) were observed in $6.5 \% \quad(n=2)$ of patients, one of whom had alcoholism. Abdominal ultrasound and liver biopsy, performed in three patients with a cumulative MTX dose of $>2 \mathrm{~g}(9.6 \%$ of patients), were within normal limits.

The duration of follow-up ranged from 3 to 51 months $( \pm 13)$. Relapse occurred in $33.3 \%(n=7)$ of patients with $>50 \%$ regrowth $(n=21)$ and in $40 \%(n=6)$ of patients with $>75 \%$ regrowth $(n=15)$. One patient developed relapse during treatment, three at the time of treatment withdrawal (after dose reduction to $<7.5$ $\mathrm{mg} /$ week), and three after a mean 6.3 months after MTX discontinuation. The pattern of alopecia at relapse was multifocal (small plaques) in six patients and AA totalis in one patient. Options for relapse management included initiation of prednisone, increase in MTX dosage, intralesional corticosteroids, or topical dithranol.

\section{DISCUSSION}

Several therapeutic options are available for the treatment of extensive or refractory AA. These include intralesional, topical, or systemic corticosteroids; minoxidil; dithranol; topical sensitizers (DNCB, DPCP); and PUVA. However, none of these modalities has proven curative or preventative action. ${ }^{6}$

Methotrexate (4-amino-N-methylpteroylglutamic acid, MTX) is a folic acid antagonist and a derivative of aminopterin. ${ }^{12}$ Approved as an antineoplastic agent in 1953 and for the treatment of psoriasis in $1971{ }^{13}$ MTX acts as an immunosuppressant and is used in the treatment of several skin conditions, such as psoriasis, bullous dermatoses, collagen storage disorders, vasculitides, neutrophilic dermatoses, and atopic dermatitis. ${ }^{13}$ Recently, it has been used in the treatment of AA, with satisfactory results. ${ }^{89,10,11}$

In the circulation, $50 \%$ of MTX is proteinbound. It exhibits particular affinity for hepatocytes, myeloid precursors, red blood cells, and fibroblasts. It is converted to its predominantly active polyglutamate metabolite, which persists for months and allows weekly dosing. ${ }^{12,13}$ Excretion is mostly renal and, to a lesser extent, biliary. ${ }^{13}$

Although the mechanism of action of MTX is not entirely understood, it is known to inhibit the enzyme dihydrofolate reductase, which leads to a decrease in intracellular reduced folate concentrations. This decrease inhibits purine and pyrimidine metabolism and, consequently, nucleic acid synthesis, thus resulting in antineoplastic effects when administered at high doses. ${ }^{11}$ MTX polyglutamates also inhibit AICAR (5-aminoimidazole-4-carboxamide ribonucleotide formyltransferase), an enzyme involved in purine synthesis, which ultimately leads to a buildup of adenosine, a mediator of many of the anti-inflammatory effects of MTX. Adenosine is released into the extracellular space and, among multiple anti-inflammatory actions, inhibits white blood cell accumulation, leads to a reduction in TNF- $\alpha$ and IFN- $\gamma$ synthesis, and inhibits a variety of monocyte, macrophage, and T-cell activities. ${ }^{12,13}$ This action might explain the effect of MTX in AA.

In this study, MTX was used in severe forms of AA (multifocal, universalis, totalis, and diffuse) to good effect ( $>50 \%$ regrowth in $67.7 \%$ of cases), with few adverse effects. These results are similar to those reported in prior studies: Joly (2010) and Droitcourt (2012) reported satisfactory regrowth in $64 \%$ and $70 \%$ of patients respectively. ${ }^{10,11}$ A study conducted in children also found no serious side effects, with $>50 \%$ regrowth in five of 13 patients assessed. ${ }^{11}$

The factors associated with a higher incidence of response (although not significantly so) were male sex, age $>40$ years, systemic corticosteroid therapy, and a cumulative MTX dose of 1001-1500 mg. Other factors, such as multifocal AA and disease duration $<5$ years, were significantly associated with response, and may thus be defined as indicators of better prognosis. A direct association between severity of AA and longterm prognosis has been demonstrated previously. ${ }^{4}$ 
The use of systemic corticosteroids in combination with MTX in the early months of treatment may mask therapeutic response. Nevertheless, it was associated with improved response, as in previous studies, although the difference was not significant in the present sample. ${ }^{8,9,10,11}$

The main short-term adverse effects are hematologic, particularly pancytopenia. Other adverse effects include mucositis, oral and/or gastrointestinal ulcers, rash, photosensitivity, acne, alopecia, anorexia, diarrhea, nausea, and interstitial pneumonitis, particularly in patients with hypoalbuminemia. Long-term adverse effects are mostly hepatic, and may range from elevated transaminases to steatosis and cirrhosis. ${ }^{12,13}$ Other long-term effects include pulmonary fibrosis, malignancy (increased risk of lymphoma in patients with psoriasis or rheumatoid arthritis), and increased risk of occlusive vascular disease (due to increased homocysteine levels). ${ }^{12}$

Based on the folate-depleting mechanism of action (both therapeutic and toxic) of MTX, studies have been conducted to assess the effect of folic acid or folinic acid supplementation given after MTX doses; all have demonstrated a reduction in adverse effects without loss of efficacy. ${ }^{13,15}$ In the present study, folic acid was administered at a dose of $5 \mathrm{mg}$ once to three times weekly.

Myelosuppression is one of the most fearsome adverse effects of MTX, due to both its severity and its unpredictability. Mild to moderate leukopenia (the most common manifestation), thrombocytopenia, and megaloblastic anemia occur in $3-24 \%$ of patients. ${ }^{12}$ In our sample, three patients $(9.7 \%)$ developed mild to moderate leukopenia, with improvement after increasing folic acid supplementation.

The risk of hepatotoxicity is increased in the presence of excess alcohol intake, concomitant retinoid therapy, diabetes mellitus, or obesity. ${ }^{13,16}$ In the present study, two patients developed increased transaminases: one with a history of alcoholism (a known risk factor) and one on concomitant nonsteroidal anti-inflammatory drug therapy, which may increase plasma levels of MTX.17,18

Regarding the safe cumulative dose of MTX, most studies have found no signs of fibrosis at cumulative doses ranging from 1 to $1.5 \mathrm{~g}$. Therefore, patients with normal baseline labs and no risk factors need not undergo hepatic biopsy until this dose is reached. ${ }^{19,20,21,22}$ The risk apparently remains low $(<2.6 \%)$ up to cumulative doses of $4 \mathrm{~g} .{ }^{23}$ Furthermore, low doses (<20 g/week) are associated with less risk. ${ }^{23}$ In the literature, the incidence of hepatic fibrosis ranges from $5.7 \%$ to $71.8 \%$. This extreme variability makes the risk of fibrosis impossible to quantify. ${ }^{24}$

Assessment of hepatic fibrosis may be performed by means of invasive (biopsy) and non-invasive (ultrasound, Fibroscan, and serum markers). ${ }^{25,26}$ In the present study, three patients with a cumulative dose $>2$ g underwent hepatic biopsy, which revealed no changes.

In our sample, the mean therapeutic dose of MTX was approximately $20 \mathrm{mg}$ and the dose required for onset of regrowth was $180 \mathrm{mg}$, i.e., onset of response took approximately 9 weeks (2.1 months). Joly (2010) and Droitcourt (2012) reported similar times to response onset: 2.5 and 3 months respectively. ${ }^{9,10}$ Most patients with $>50 \%$ regrowth received cumulative doses in the $1000-1500 \mathrm{mg}$ range $(87 \%)$, which suggests that these dose levels must be achieved before therapeutic response can be assessed.

A previous study found an $80 \%$ relapse rate in MTX-treated patients who experienced regrowth. ${ }^{9}$ In our sample, relapse occurred in $33.3 \%(n=7)$ of patients with $>50 \%$ regrowth $(n=21)$, and in $20 \%$ of patients with $>75 \%$ regrowth. One patient developed relapse during treatment, three at the time of treatment withdrawal (after dose reduction to $<7.5$ $\mathrm{mg}$ /week), and three a mean 6.3 months after MTX discontinuation, which suggests that an MTX dose of $7.5 \mathrm{mg} /$ week is a good level to define the timing of drug discontinuation or the minimum effective dose for maintenance of remission.

\section{CONCLUSION}

MTX at a mean dose of $20 \mathrm{mg} /$ week appears to be a safe and promising option for the treatment of severe forms of AA. A mean cumulative dose of 180 $\mathrm{mg}$ was required for onset of response, and total cumulative doses of $1000-1500 \mathrm{mg}$ were associated with the best responses.

Limitations of this study include the heterogeneity of the sample (patients recruited from a public hospital and from private practices), as well as the retrospective, non-comparative nature of the study. Larger samples studied in a blind, randomized fashion are required to establish MTX as first-line therapy for AA. The use of biomarkers currently in development for patient monitoring may encourage longterm use of MTX without requiring patients to undergo invasive testing. $\square$ 


\section{REFERENCES}

1. Rivitti E. Alopecia areata: a revision and update. An Bras Dermatol. 2005;80:57-68.

2. Alkhalifah A, Alsantali A, Wang E, McElwee KJ, Shapiro J. Alopecia areata update Part I. Clinical picture, histopatology and pathogenesis. J Am Acad Dermatol. 2010;62:177-88.

3. Sbd.org.br [Internet]. Sociedade Brasileira de Dermatologia. Censo Dermatológico da SBD. [acesso 1 Dez 2011]. Disponível em: http://www.sbd.org.br/down/censo_ dermatologic02006.pdf.

4. Tosti A, Bellavista S, Iorizzo M. Alopecia areata: A long term follow-up study of 191 patients. J Am Acad Dermatol. 2006;55:438-41.

5. Gilhar A, Paus R, Kalish RS. Lymphocytes, neuropeptides, and genes involved in alopecia areata. J Clin Invest. 2007;117:2019-27.

6. Gregoriou S, Papafragkaki D, Kontochristopoulos G, Rallis E, Kalogeromitros D, Rigopoulos D. Cytokines and Other Mediators in Alopecia Areata. Mediators Inflamm. 2010;2010:928030.

7. Alkhalifah A, Alsantali A, Wang E, McElwee KJ, Shapiro J. Alopecia areata update, Part II. Treatment. J Am Acad Dermatol. 2010;62:191-202.

8. Joly P. The use of methotrexate alone or in combination with low doses of oral corticosteroids in the treatment of alopecia totalis or universalis. J Am Acad Dermatol. 2006;55:632-6.

9. Chartaux E, Joly P. Long-term follow-up of the efficacy of methotrexate alone or in combination with low doses of oral corticosteroids in the treatment of alopecia areata totalis or universalis. Ann Dermatol Venereol. 2010;137:507-13.

10. Droitcourt C, Milpied B, Ezzedine K, Hubiche T, Belin E, Akpadjan F, et al. Interest of High-Dose Pulse Corticosteroid Therapy Combined with Methotrexate for Severe Alopecia Areata: A Retrospective Case Series. Dermatology. 2012;224:369-73.

11. Royer M, Bodemer C, Vabres P, Pajot C, Barbarot S, Paul C, et al. Efficacy and tolerability of methotrexate in severe childhood AA. Br J Dermatol. 2011;165:407-10.

12. Neves C, Jorge R, Barcelos A. A Teia de Toxicidade do Metotrexato. Acta Reumatol Port. 2009; 34:11-34.

13. Bressan AL, Silva RS, Fontenelle E, Gripp AC. Immunosuppressive agents in Dermatology. An Bras Dermatol. 2010;85:9-22.

14. Conde MB, Melo FAF, Marques AMC, Cardoso NC, Pinheiro VGF, Dalcin PTR, et al. III Brazilian Thoracic Association Guidelines on Tuberculosis. J Bras Pneumol. 2009;35:1018-48.

15. Prey S, Paul C. Effect of folic or folinic acid supplementation on methotrexate-associated safety and efficacy in inflammatory disease: a systematic review. $\mathrm{Br} \mathrm{J}$ Dermatol. 2009;160:622-8.

16. Berends MA, Snoek J, de Jong EM, van de Kerkhof PC, van Oijen MG, van Krieken $\mathrm{JH}$, et al. Liver injury in long-term methotrexate treatment in psoriasis is relatively infrequent. Aliment Pharmacol Ther. 2006;24:805-11.

17. Lebwohl M, Ali S. Treatment of psoriasis. Part 2. Systemic therapies. J Am Acad Dermatol. 2001;45:649-61

18. Martins G.A, Arruda L. Systemic treatment of psoriasis - Part I: methotrexate and acitretin. An Bras Dermatol. 2004;79:263-78.

19. Aithal GP, Haugk B, Das S, Card T, Burt AD, Record CO. Monitoring methotrexateinduced hepatic fibrosis in patients with psoriasis: are serial liver biopsies justified? Aliment Pharmacol Ther. 2004;19:391-9.

20. Carneiro SC, Cássia FF, Lamy F, Chagas VL, Ramos-e-Silva M. Methotrexate and liver function: a study of 13 psoriasis cases treated with different cumulative dosages. J Eur Acad Dermatol Venereol. 2008;22:25-9.
21. Roenigk HH Jr, Auerbach R, Maibach H, Weinstein G, Lebwohl M. Methotrexate in psoriasis: consensus conference. J Am Acad Dermatol. 1998;38:478-85.

22. Lebwohl M, Ali S. Treatment of psoriasis. Part 2. Systemic therapies. J Am Acad Dermatol. 2001;45:649-61.

23. Thomas JA, Aithal GP. Monitoring Liver Function during Methotrexate Therapy for Psoriasis. Are Routine Biopsies Really Necessary? Am J Clin Dermatol. 2005;6:357-63.

24. Montaudié H, Sbidian E, Paul C, Maza A, Gallini A, Aractingi S, et al. Methotrexate in psoriasis: a systematic review of treatment modalities, incidence, risk factors and monitoring of liver toxicity. J Eur Acad Dermatol Venereol. 2011;25:12-8.

25. Barker J, Horn EJ, Lebwohl M, Warren RB, Nast A, Rosenberg W, et al. Assessment and management of methotrexate hepatotoxicity in psoriasis patients: report from a consensus conference to evaluate current practice and identify key questions toward optimizing methotrexate use in the clinic. J Eur Acad Dermatol Venereol. 2011;25:758-64

26. Laharie D, Seneschal J, Schaeverbeke T, Doutre MS, Longy-Boursier M, Pellegrin JL, et al. Assessment of liver fibrosis with transient elastography and FibroTest in patients treated with methotrexate for chronic inflammatory diseases: A case-control study. J Hepatol. 2010;53:1035-40.
MAILING ADDRESS:
Mariana Hammerschmidt
Rua General Carneiro, 181
80060-900 - Curitiba - PR
Brazil
E-mail: mari-hammer@hotmail.com

How to cite this article: Hammerschmidt M, Mulinari-Brenner F. Efficacy and safety of methotrexate in alopecia areata. An Bras Dermatol. 2014;89(5):729-34. 